ARTICLE

Received 22 Jan 2014 | Accepted 2 Jul 2014 | Published 1 Aug $2014 \quad$ DOl: 10.1038/ncomms5578

\title{
Liquid-metal electrode to enable ultra-low temperature sodium-beta alumina batteries for renewable energy storage
}

Xiaochuan Lu', Guosheng $\mathrm{Li}^{1}$, Jin Y. Kim¹, Donghai Mei ${ }^{2}$, John P. Lemmon', Vincent L. Sprenkle ${ }^{1}$ \& Jun Liu ${ }^{1}$

Commercial sodium-sulphur or sodium-metal halide batteries typically need an operating temperature of $300-350^{\circ} \mathrm{C}$, and one of the reasons is poor wettability of liquid sodium on the surface of beta alumina. Here we report an alloying strategy that can markedly improve the wetting, which allows the batteries to be operated at much lower temperatures. Our combined experimental and computational studies suggest that addition of caesium to sodium can markedly enhance the wettability. Single cells with $\mathrm{Na}-\mathrm{Cs}$ alloy anodes exhibit great improvement in cycling life over those with pure sodium anodes at 175 and $150^{\circ} \mathrm{C}$. The cells show good performance even at as low as $95^{\circ} \mathrm{C}$. These results demonstrate that sodium-beta alumina batteries can be operated at much lower temperatures with successfully solving the wetting issue. This work also suggests a strategy to use liquid metals in advanced batteries that can avoid the intrinsic safety issues associated with dendrite formation.

\footnotetext{
${ }^{1}$ Energy and Environment Directorate, Pacific Northwest National Laboratory, Richland, Washington 99352, USA. ${ }^{2}$ Fundamental and Computational Sciences Directorate, Pacific Northwest National Laboratory, Richland, Washington 99352, USA. Correspondence and requests for materials should be addressed to X.L. (email: Xiaochuan.Lu@pnnl.gov) or to J.Y.K. (email: Jin.Kim@pnnl.gov).
} 
A mong all types of anode materials, metals such as lithium and sodium have the highest capacity and great potential to increase the energy density of batteries. Unfortunately, these metal anodes have had very limited applications so far in practical devices owing to dendrite formation, passivation of the surface layer and other problems $s^{1,2}$. Dendrite growth is one of the reasons for safety concerns in current battery devices. One approach to address this problem is to use molten or liquid metal electrodes. This concept has been explored in several types of batteries such as liquid-metal batteries ${ }^{3}$, Li-ion batteries ${ }^{4}$ and $\mathrm{Na}$ batteries ${ }^{5}$, and successfully used in sodium-beta alumina batteries $(\mathrm{NBBs})^{6-8}$, which are based on a molten sodium anode and $\beta^{\prime \prime}-\mathrm{Al}_{2} \mathrm{O}_{3}$ solid electrolyte (BASE). Currently, NBBs such as sodium-sulphur $(\mathrm{Na}-\mathrm{S})$ battery and sodium-metal halide (ZEBRA) batteries are among the most promising technologies for large-scale renewable energy storage because of their high theoretical specific energy, high energy efficiency and good cycle life ${ }^{6,7}$. These technologies have already been in commercial production and widely tested as grid storage and a supplement to wind and solar installations in Japan, France and the United States ${ }^{9}$.

However, high operating temperatures (for example, $300-350^{\circ} \mathrm{C}$ ) are required for battery components to achieve satisfactory electrochemical activity in NBBs. The BASE shows a sufficient ionic conductivity $\left(\sim 0.2 \mathrm{~s} \mathrm{~cm}^{-1}\right)$ for battery applications only at temperatures of $250^{\circ} \mathrm{C}$ or above $e^{7}$. As for the anode, molten sodium appears to not fully wet the surface of BASE below $400^{\circ} \mathrm{C}$ (refs $7,10,11$ ). The poor sodium wetting is one of most challenging issues in NBBs; it is related to formation of a surface oxide film ${ }^{7,10,12-14}$. Moisture absorbed on the BASE surface could react with sodium to form a surface layer of sodium oxide, which impedes sodium dissolution and sodium ion transport across the sodium anode/BASE interface ${ }^{12,15,16}$. Impurities such as calcium in the BASE may also deteriorate the sodium wettability during long-term cell cycling ${ }^{7,10,14,17}$. Calcium ions migrate to the interface and form a calcium-oxide film, which blocks contact between the sodium and BASE ${ }^{18-20}$. The high operation temperature significantly increases battery manufacturing and maintenance costs, and causes safety concerns as well. A few safety incidents during the past few years have had a profoundly negative impact on the broad commercialization and implementation of these technologies ${ }^{21}$.
Great efforts have been made to modify the sodium anode/ BASE interface to improve wetting, such as coating the BASE surface with a thin layer of lead ${ }^{22}$, bismuth ${ }^{22}$ or $\operatorname{tin}^{16,22}$, or adding titanium and aluminium into the sodium anode as oxygen getters ${ }^{20,23}$. The combination of these techniques has been proven to successfully eliminate the interfacial effects and resolve the wetting issue at temperatures above $300^{\circ} \mathrm{C}$. However, these techniques appear to be ineffective at lower temperatures, particularly below $200^{\circ} \mathrm{C}$ (ref. 24).

Here we propose a new strategy to enable the use of liquidmetal electrodes at much lower temperatures via alloying. In particular, we develop novel $\mathrm{Na}$ alloys, such as $\mathrm{Na}-\mathrm{K}, \mathrm{Na}-\mathrm{Rb}$ and $\mathrm{Na}-\mathrm{Cs}$ as anode materials for NBBs. Computational and experimental studies suggest that these alloys, particularly the $\mathrm{Na}$-Cs alloy, thoroughly change the wetting of sodium on the BASE surface. This strategy is much more effective than any other types of modifications or treatments of the BASE or sodium anode so far, particularly at lower temperatures. Moreover, the addition of these metals to sodium lowers the melting point ${ }^{25-27}$. Therefore, with this technology, new NBBs can be operated at much lower temperatures. $\mathrm{Na}-\mathrm{S}$ and $\mathrm{Na}-\mathrm{NiCl}_{2}$ cells with the $\mathrm{Na}-$ Cs alloy show excellent cycling performance at lower temperatures (for example, 175 and $150^{\circ} \mathrm{C}$ ). These cells even can be operated at temperature as low as $95^{\circ} \mathrm{C}$ with good performance. The reduced operation temperature will simplify battery design/manufacturing and improve battery durability and safety, which eventually will make NBBs competitive with other existing technologies for stationary applications. This work also suggests a new general route of using light-weight liquid metals as electrodes for next-generation safe, high-energy density batteries. Compared with other approaches, such as room-temperature $\mathrm{Na}$ and Li-ion batteries, the NBBs with liquid alloys and dense solid electrolytes will not have issues such as dendrite growth, reaction and inter-diffusion between cell components and so on.

\section{Results}

Wetting behaviour of $\mathrm{Na}$ and $\mathrm{Na}$ alloys on BASE surface. The new concept is based on the fact that wetting between different surfaces is generally affected by surface energy. The surface energy and wetting are sensitive to atomic composition near the interface. Figure 1 shows images of pure $\mathrm{Na}$ and various types of

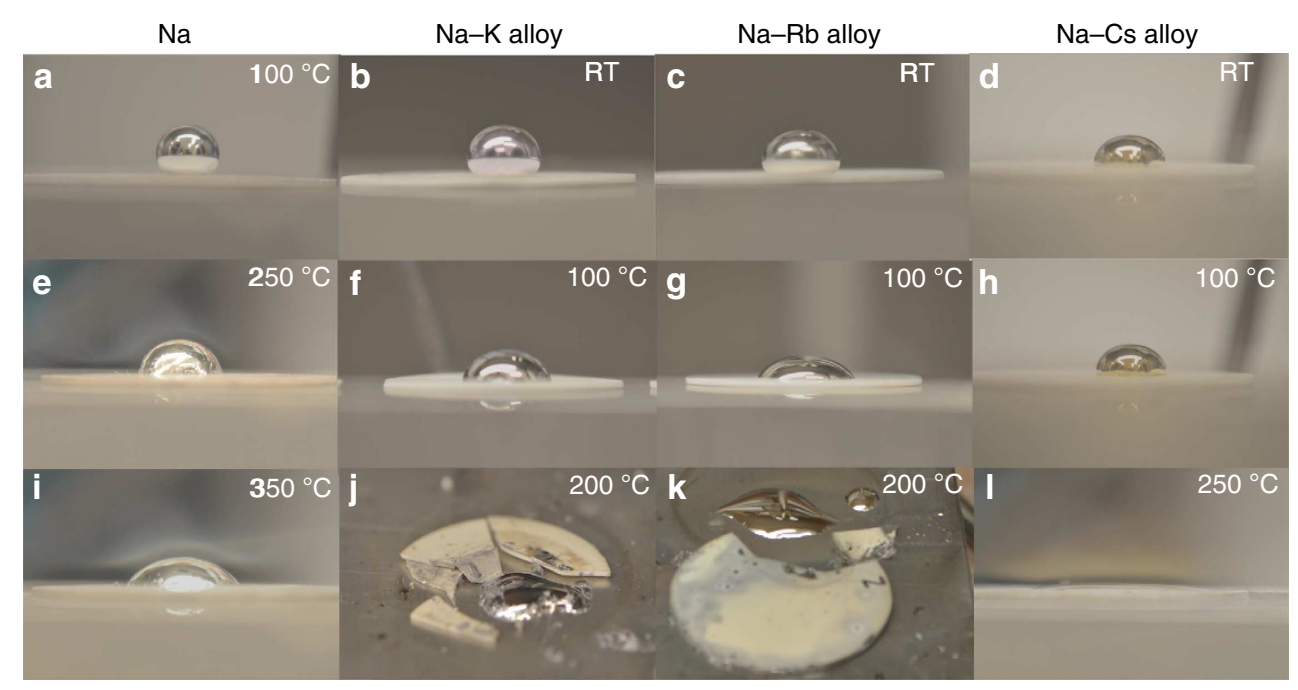

Figure 1 | Wetting behaviour of $\mathbf{N a}$ and $\mathbf{N a}$ alloys on BASE surface. (a,e,i) Liquid Na drops on untreated BASE. (b,f,j) Liquid Na-K alloy (molar ratio of 3:7) on untreated BASE. (c,g,k) Liquid Na-Rb alloy (molar ratio of 1:4) on untreated BASE. (d,h, I) Liquid Na-Cs alloy (molar ratio of 1:4) drops on untreated BASE. 
$\mathrm{Na}$ alloys on pristine or untreated BASE at various temperatures. Pure sodium did not wet the untreated surface at $100^{\circ} \mathrm{C}$, but formed a compact liquid droplet, as shown in Fig. 1a. Although the wetting gradually improved with temperature, full wetting on the fresh surface was not observed at temperatures below $400^{\circ} \mathrm{C}$. For example, the contact angle was as high as $52^{\circ}$ at $350^{\circ} \mathrm{C}$ (see Fig. 1i; Table 1), indicating incomplete wetting of pure sodium on the untreated BASE, which is in agreement with the literature ${ }^{7,10}$. Compared with pure sodium, significant improvement in wettability was achieved for $\mathrm{Na}$ alloys, as shown in Fig. 1 . Even at room temperature, wetting improved gradually from $\mathrm{Na}-\mathrm{K}$, to $\mathrm{Na}-\mathrm{Rb}$, to $\mathrm{Na}-\mathrm{Cs}$. At $100^{\circ} \mathrm{C}$, all three alloys showed partial wetting on the fresh BASE with contact angles of $91^{\circ}, 62.4^{\circ}$ and $88.6^{\circ}$, which are comparable to that of pure sodium at $250^{\circ} \mathrm{C}$. When heated to $200^{\circ} \mathrm{C}$, the BASE samples coated with $\mathrm{Na}-\mathrm{K}$ and $\mathrm{Na}-\mathrm{Rb}$ alloys were fractured (see Fig. 1j,k). This might be due to ion exchange of $\mathrm{Na}^{+}$by $\mathrm{K}^{+}$and $\mathrm{Rb}^{+}$, considering that $\mathrm{K}^{+}$and $\mathrm{Rb}^{+}$are only slightly larger than $\mathrm{Na}^{+}(1.33$ and 1.47 versus $0.97 \AA$ ). Direct replacement of $\mathrm{Na}^{+}$by $\mathrm{K}^{+}$and $\mathrm{Rb}^{+}$has been observed via treatment of beta alumina with the corresponding molten nitrates ${ }^{28}$. The ion exchange in a polycrystalline body typically causes permanent stresses at the grain boundaries due to changes in crystal axis dimensions ${ }^{28,29}$, which might be responsible for the observed fracture in the current study.

As for $\mathrm{Cs}^{+}$, the equilibrium is unfavourable for direct replacement of $\mathrm{Na}^{+}$by Cs ${ }^{+}$in beta alumina due to the significantly larger size of $\mathrm{Cs}^{+}(1.69 \AA)$. As a result, no fracture or crack was observed for the BASE sample coated with $\mathrm{Na}-\mathrm{Cs}$ alloy even heated to $350^{\circ} \mathrm{C}$. The liquid Na-Cs spread over the entire surface at $250^{\circ} \mathrm{C}$ with a contact angle of $\sim 0^{\circ}$ (see Fig. 1l), indicating complete wetting on the surface. The detailed wetting behaviour for the $\mathrm{Na}-\mathrm{Cs}$ alloy is compared with pure sodium (Supplementary Fig. 1) and the corresponding contact angles are listed in Table 1. It can be seen that the wettability of sodium on the untreated BASE was thoroughly changed with the addition of caesium. When caesium was added to sodium, similar wetting performance was achieved at a temperature at least $150^{\circ} \mathrm{C}$ lower, as shown in Table 1 . Once the Na-Cs alloy was wetting the BASE surface at higher temperatures, the wetting behaviour would be maintained even after the sample was cooled down to room temperature, which was similar to that of pure sodium ${ }^{7,10}$. As mentioned earlier, coating the BASE surface with a thin layer of lead $\mathrm{d}^{22}$, bismuth ${ }^{22}$ or $\operatorname{tin}^{16,22}$ is typically carried out to improve the wetting. In the current study, the addition of caesium into sodium seemed more effective than these treatments, as compared in Supplementary Fig. 1. The observed sodium-oxide film (Supplementary Fig. 1c) was due to reaction between sodium and $\mathrm{Pb} / \mathrm{PbO}$ coating on the BASE. As mentioned in the experimental section, the BASE surface was coated with lead acetate aqueous solution and the coating decomposed to lead oxide following heat treatment. The lead oxide reacted with sodium to form a sodium-oxide surface layer during wetting tests.

As discussed previously, the incomplete wetting of sodium on the BASE surface is likely related to surface moisture and formation of an oxide film ${ }^{7,10,12-14}$. Titanium or aluminium is typically added to sodium as an oxygen getter to minimize the formation of sodium oxide at the interface and improve wetting ${ }^{20,23}$. This type of explanation may not be applicable to potassium, rubidium and caesium. As shown in Supplementary Table 1, the standard Gibbs free energies of formation of $\mathrm{K}_{2} \mathrm{O}$, $\mathrm{Rb}_{2} \mathrm{O}$ and $\mathrm{Cs}_{2} \mathrm{O}$ are $-322.1,-294.3$ and $-327.2 \mathrm{~kJ} \mathrm{~mol}^{-1}$, respectively (http://bachiller.sabuco.com/fq/quimica/tablas-entalpiasinorganicos.pdf) (http://kinetics.nist.gov/janaf/). They are higher than those for $\mathrm{Na}_{2} \mathrm{O}$ and $\mathrm{CaO}$ (compared in Supplementary Table 1), which means these oxides are less stable than the latter two. This trend of Gibbs free energies also can be applied at high temperatures (http://kinetics.nist.gov/janaf/). Therefore, potassium, rubidium or caesium cannot act as oxygen getters like titanium or aluminium, and react with $\mathrm{Na}_{2} \mathrm{O}$ or $\mathrm{CaO}$ to form the corresponding metal oxides. We conclude that the addition of these metals into sodium is unlikely to break down the oxide film on the BASE.

Computational modelling of wetting process. To get fundamental insight into the mechanism towards the improved wetting via alloying, simulation of the wetting process was carried out with the Na-Cs alloy. Fifty-atom clusters of sodium or Na-Cs alloy were taken from the initial configuration in their crystal bulk structures. Droplets containing the clusters were set on BASE substrate until equilibrium at various temperatures. Images of the droplets after equilibrium are shown in Fig. 2; Supplementary Fig. 2. Corresponding heights and widths of the droplets were measured and are listed in Supplementary Table 2. It can be seen that the height decreased while width increased with higher caesium content in the droplets, which clearly indicated that the wetting gradually improved with the increase of caesium concentration in the alloys. These results were generally in agreement with our experimental observations with various $\mathrm{Na}-\mathrm{Cs}$ alloy compositions, particularly at $150^{\circ} \mathrm{C}$ (Supplementary Fig. 3).

Theoretically, wettability of a liquid-metal droplet on a solid surface can be determined by the work of adhesion, $W_{\text {adh }}$ defined as ${ }^{30}$

$$
W_{\mathrm{adh}}=\gamma_{\mathrm{S}}+\gamma_{\mathrm{M}}-\gamma_{\mathrm{I}}
$$

where $\gamma_{S}, \gamma_{M}$ and $\gamma_{I}$ are surface energies of solid-surface vacuum (S), liquid-metal vacuum (M) and interfacial energy of liquidmetal-solid-surface (I). According to the Young-Dupré equation ${ }^{30}$,

$$
\frac{W_{\text {adh }}}{\gamma_{\mathrm{M}}}=1+\cos \theta
$$

Therefore, better wettability (that is, smaller contact angle, $\theta$ ) is directly related to a larger ratio of $W_{\text {adh }} / \gamma_{\mathrm{M}}$. Compared with sodium $\left(\gamma_{\mathrm{Na}}=\sim 150 \mathrm{dyn}_{\mathrm{cm}}{ }^{-1}\right)$, the surface tension of liquid caesium metal is much lower $\left(\gamma_{\mathrm{Cs}}=\sim 60 \mathrm{dyn} \mathrm{cm}^{-1}\right)$ in the studied temperature range ${ }^{31}$. The calculated $W_{\text {adh }}$ for the caesium/ $\beta^{\prime \prime}$-alumina system is $121.9 \mathrm{dyn}^{-1}$, which is larger than that for the sodium $/ \beta^{\prime \prime}$-alumina system $\left(65.3 \mathrm{dyn} \mathrm{cm}^{-1}\right)$,

\begin{tabular}{|c|c|c|c|c|c|c|}
\hline & RT & $100^{\circ} \mathrm{C}$ & $150^{\circ} \mathrm{C}$ & $200^{\circ} \mathrm{C}$ & $250^{\circ} \mathrm{C}$ & $350^{\circ} \mathrm{C}$ \\
\hline Pure sodium on untreated BASE & - & Non-wetting & Non-wetting & $100.2 \pm 1.5$ & $75.7 \pm 1.8$ & $52.0 \pm 2.7$ \\
\hline $\mathrm{Na}-\mathrm{K}$ (molar ratio of $3: 7$ ) on untreated BASE & $127.6 \pm 1.6$ & $91.0 \pm 1.9$ & - & - & - & - \\
\hline $\mathrm{Na}-\mathrm{Rb}$ (molar ratio of $1: 4$ ) on untreated BASE & $112.5 \pm 1.7$ & $62.4 \pm 2.5$ & - & - & - & - \\
\hline $\mathrm{Na}-\mathrm{Cs}$ (molar ratio of $1: 4$ ) on untreated BASE & $90.6 \pm 1.4$ & $88.6 \pm 2.3$ & $42.0 \pm 2.3$ & $27.4 \pm 2.8$ & $2.2 \pm 1.0$ & - \\
\hline
\end{tabular}

Table 1 | Contact angles $\left(^{\circ}\right)$ calculated from Fig. 1 and Supplementary Fig. 1. 
based on the stronger interactions between caesium and $\beta^{\prime \prime}$-alumina atoms. The larger $W_{\text {adh }}$ and smaller $\gamma_{M}$ for caesium means a smaller wetting angle and, therefore, better wettability on the $\beta^{\prime \prime}$-alumina surface than sodium, as observed in the current study. As evidence, the interface between the BASE and $\mathrm{Na}-\mathrm{Cs}$ alloy after wetting tests was analysed using scanning electron microscopy/energy-dispersive X-ray spectrometry (SEM/ EDS) (Supplementary Fig. 4). The EDS line scan was performed from the BASE/Na-Cs alloy interface (left) to the alloy surface (right). From the EDS line scan, it can be seen that caesium concentration in the anode gradually deceased from the BASE/
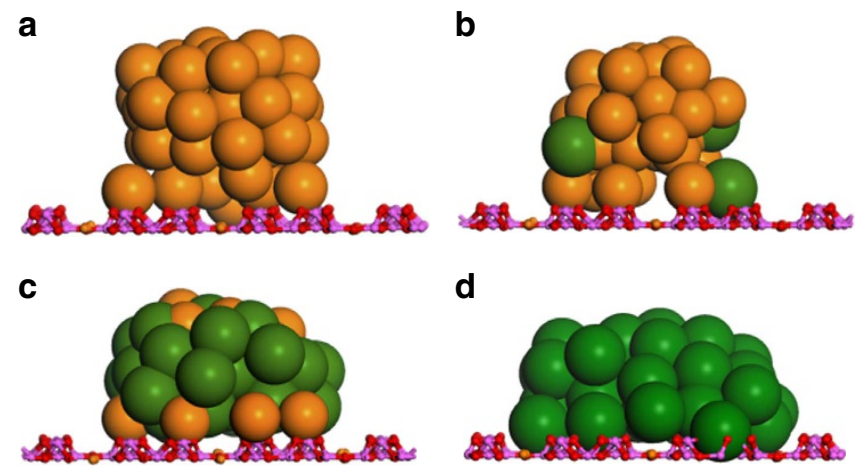

Figure 2 | Simulated structures of liquid Na-Cs alloy droplets on BASE at $100^{\circ} \mathbf{C}$. (a) $\mathrm{Na}$, (b) $\mathrm{Na}-\mathrm{Cs}$ (molar ratio of 4:1), (c) Na-Cs (molar ratio of 1:4) and (d) Cs liquid. The $\mathrm{Al}, \mathrm{O}, \mathrm{Na}$ and $\mathrm{Cs}$ are coloured purple, red, orange and dark green, respectively. The larger ball of $\mathrm{Na}$ and $\mathrm{Cs}$ in the droplets is used for graphical purpose.
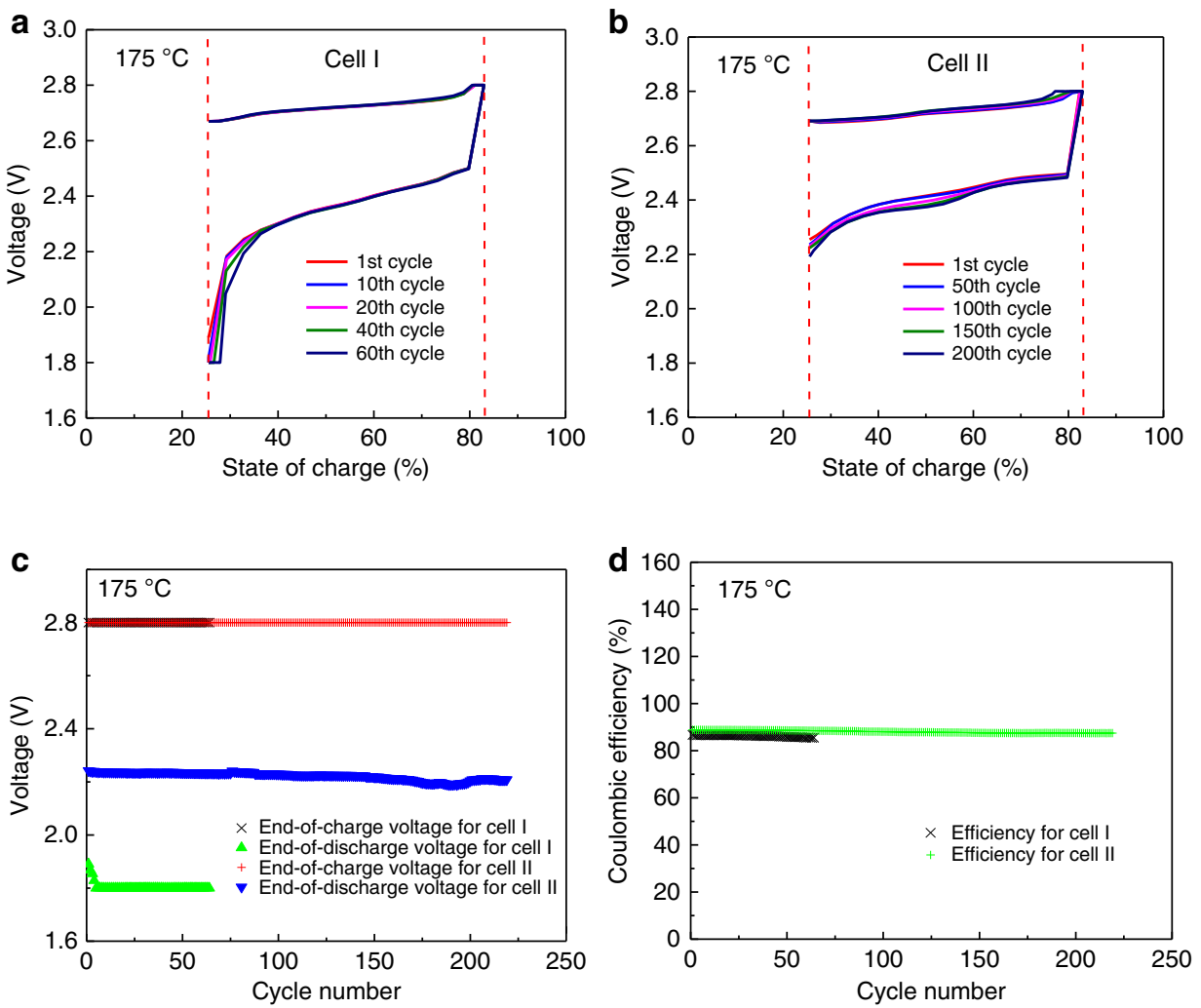

Figure 3 | Electrochemical cell performance. Cell I: $\mathrm{Na} \mid \mathrm{Pb}$-treated $\mathrm{BASE} \mid \mathrm{NiCl}{ }_{2}$ with $\mathrm{NaAlCl}_{4}$. Cell II: $\mathrm{Na}-\mathrm{Cs} \mid$ untreated $\mathrm{BASE} \mid \mathrm{NiCl} \mathrm{N}_{2}$ with $\mathrm{NaAICl}$. (a) Cell voltage profiles for cell I during the 1st, 10th, 20th, 40th and 60th cycles at $175^{\circ} \mathrm{C}$. (b) Cell voltage profiles for cell II during the 1 st, 50 th, 100th, 150th and 200th cycles at $175^{\circ} \mathrm{C}$. (c) End-of-charge and -discharge voltage for cells I and II during cycling. (d) Coulombic efficiency for cells I and II during cycling. alloy interface to the alloy surface while the opposite trend was observed for sodium. More detailed chemical composition along the line scan is listed in the Table. All of these results generally agreed with our simulation results that interactions between caesium and $\beta^{\prime \prime}$-alumina atoms are stronger than those between sodium and $\beta^{\prime \prime}$-alumina atoms, and more caesium atoms tend to distribute at the interface. This type of explanation can also be applied to the improved wetting of $\mathrm{Na}-\mathrm{K}$ and $\mathrm{Na}-\mathrm{Rb}$ alloys on BASE (refer to Fig. 1), considering their lower surface tension ${ }^{31}$ and larger $W_{\text {adh }}$ (Supplementary Table 3 ).

Electrochemical cell performance with $\mathrm{Na}-\mathrm{Cs}$ alloy. To further investigate the performance of the $\mathrm{Na}-\mathrm{Cs}$ alloy as anode material for NBBs, single cells with the Na-Cs alloy anode and untreated BASE were evaluated and compared with those with pure sodium and treated BASE. Figure 3 shows the cycling performance of $\mathrm{Na}-\mathrm{NiCl}_{2}$ cells with $\mathrm{Na}-\mathrm{Cs}$ and pure sodium anodes at $175^{\circ} \mathrm{C}$. The cells were cycled between 26 and $83 \%$ of cell capacity (for example, $160 \mathrm{mAh}$ ), as described previously ${ }^{24}$. The SOC (state of charge) of $26-83 \%$ was selected based on the fact that, when the cell is overcharged to an SOC of $80 \%$ or above, the cell voltage is typically around $2.8 \mathrm{~V}$ or higher, and the overcharge may lead to electrochemical reactions between $\mathrm{Ni}$ and $\mathrm{NaAlCl}_{4}$ catholyte, which eventually will cause battery performance degradation during long-term cycling ${ }^{7}$. If the cell is overdischarged to an SOC of lower than $20 \%$, high cell resistance may be incurred at the end of discharge due to insufficient sodium for electrical contact between sodium and the BASE active surface. According to our previous results, the cycling window gradually shifted to the more discharged state due to higher cell resistance at $175^{\circ} \mathrm{C}$ (ref. 24). Therefore, in the current study, the cells were cycled in a two-step 
a
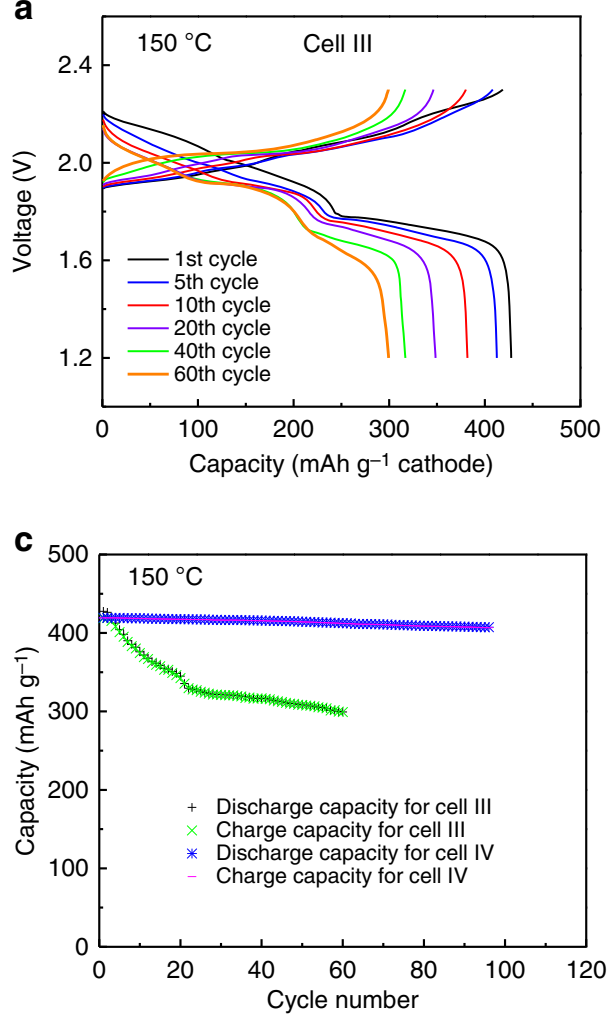

b
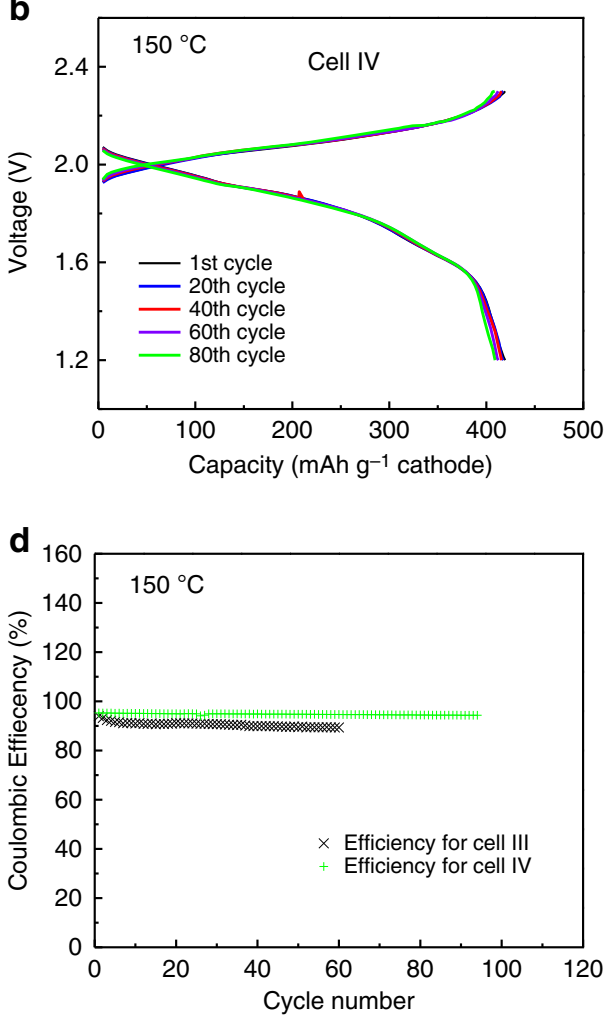

Figure 4 | Electrochemical cell performance. Cell III: Na|Pb-treated BASE|S with tetraglyme plus $1 \mathrm{M}$ Nal. Cell IV: Na-Cs|untreated BASE|S with tetraglyme plus $1 \mathrm{M} \mathrm{Nal}$. (a) Cell voltage profiles for cell III during the 1st, 5th, 10th, 20th, 40 th and 60 th cycles at $150^{\circ} \mathrm{C}$. (b) Cell voltage profiles for cell IV during the 1st, 20th, 40th, 60th and 80th cycles at $150^{\circ} \mathrm{C}$. (c) Discharge/charge capacities for cells III and IV during cycling. (d) Coulombic efficiency for cells III and IV during cycling.

charge/discharge process to maintain the capacity window. The first-step charge was under a constant current of $20 \mathrm{~mA}(\mathrm{C} / 4.5)$, and once the voltage reached $2.8 \mathrm{~V}$, the second step was started under a constant voltage of $2.8 \mathrm{~V}$ until a total capacity of $90 \mathrm{mAh}$ was reached. The two-step discharge was similar, including one step under a constant current of $30 \mathrm{~mA}$, followed by a second step at a constant voltage of $1.8 \mathrm{~V}$.

As can be seen in Fig. 3a,b, the charge profiles for both cells were identical, while significant differences were observed at the end of discharge. The end-of-discharge voltage for the cell with the $\mathrm{Na}-\mathrm{Cs}$ alloy anode was $\sim 2.2 \mathrm{~V}$ and remained stable over 200 cycles (see Fig. $3 \mathrm{c}$ ), while a precipitous voltage drop at the end of discharge was observed for the cell with the pure sodium anode. The end-of-discharge voltage started at $1.9 \mathrm{~V}$ and rapidly decreased to $1.8 \mathrm{~V}$ in the first five cycles. Further decrease in the voltage caused the second-step discharge involved. As discussed previously, the precipitous voltage drop was related to either diffusion limitation in the $\mathrm{NaAlCl}_{4}$ catholyte or poor sodium wetting in the anode at low temperatures ${ }^{2}$. Since the main differences between the current two cells were different anodes along with treated or untreated BASE (that is, sodium wettability), it can be concluded that the gradual voltage drop at the end of discharge in Fig. 3a was due to insufficient wetting on the lead-treated BASE with cycling. For the cell with the Na-Cs alloy anode, however, the end-of-discharge voltage was stable over 200 cycles with negligible degradation. This clearly demonstrated that, in addition to the initial wetting performance, excellent cycle life was achieved in $\mathrm{Na}-\mathrm{NiCl}_{2}$ cells with the $\mathrm{Na}-\mathrm{Cs}$ alloy as anode material. As discussed earlier in the description of the wetting tests, it was believed that there was no ion exchange between $\mathrm{Na}^{+}$and $\mathrm{Cs}^{+}$due to the significantly larger size of $\mathrm{Cs}^{+}$than $\mathrm{Na}^{+}$(that is, 1.69 versus $0.97 \AA$ ). To verify that, we have run post analysis of the cell after 200 cycles and a cross-section of the BASE was analysed using SEM/EDS. As shown in Supplementary Fig. 5, no Cs was detected in the BASE after long-term operation, which therefore confirmed that there was no exchange between $\mathrm{Cs}^{+}$and $\mathrm{Na}^{+}$.

The performance of a $\mathrm{Na}-\mathrm{Cs}$ alloy anode was also demonstrated for a $\mathrm{Na}-\mathrm{S}$ battery. Previously, we reported an intermediate-temperature (that is, $150{ }^{\circ} \mathrm{C}$ ) $\mathrm{Na}-\mathrm{S}$ battery that uses pure sodium as the anode, BASE as the electrolyte separator and tetraglyme as the catholyte solvent ${ }^{32}$. The cell showed significant improvement in cycle life over state-of-the-art low- or roomtemperature $\mathrm{Na}-\mathrm{S}$ batteries because of the dense ceramic membrane ${ }^{32,33}$. Figure 4 compares the performance of $\mathrm{Na}-\mathrm{S}$ cells with $\mathrm{Na}-\mathrm{Cs}$ alloy and pure sodium anodes. The cells were cycled under constant current of $7 \mathrm{~mA}\left(=2.33 \mathrm{~mA} \mathrm{~cm}^{-2}\right)$ with the cutoff voltage between 1.2 and $2.3 \mathrm{~V}$. It can be seen that the initial charge/discharge profiles for both cells at $7 \mathrm{~mA}$ (that is, $\sim \mathrm{C} / 8$ ) were similar, with a capacity of $\sim 420 \mathrm{mAhg}^{-1}$; however, substantial change in cell voltage was observed for the cell with the pure sodium anode and $\mathrm{Pb}$-treated BASE during long-term cycling, which was similar to the observations in the $\mathrm{Na}-\mathrm{NiCl}_{2}$ cell (Fig. 3a,c). The charge/discharge cycling in the $\mathrm{Na}-\mathrm{S}$ cells was controlled by the voltage limit, so the change in voltage caused capacity fade with time. As seen in Fig. 4a,c, $>30 \%$ of the capacity fade was observed for the $\mathrm{Na}-\mathrm{S}$ cell with the sodium anode and $\mathrm{Pb}$-treated BASE during 60 cycles. However, the cell with the $\mathrm{Na}-\mathrm{Cs}$ alloy anode only showed slight degradation, with a capacity fade rate of $<3 \%$ over 100 cycles (Fig. 4b,c). These observations were in agreement with those for the $\mathrm{Na}-\mathrm{NiCl}_{2}$ cell, indicating significant improvement in 
a

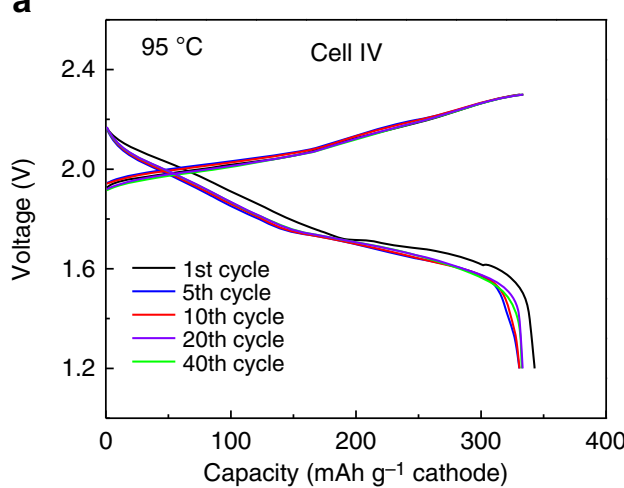

C

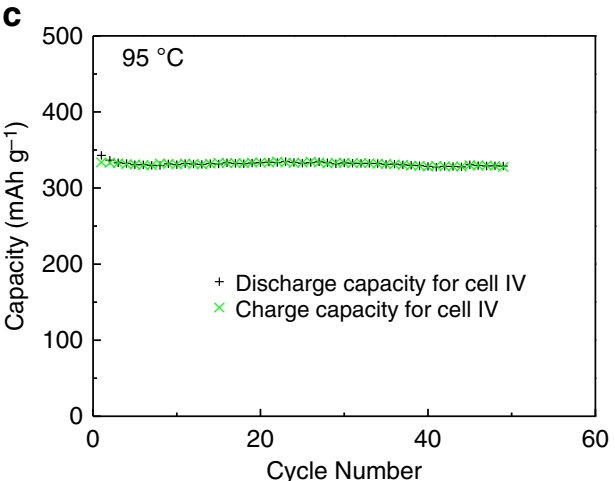

b

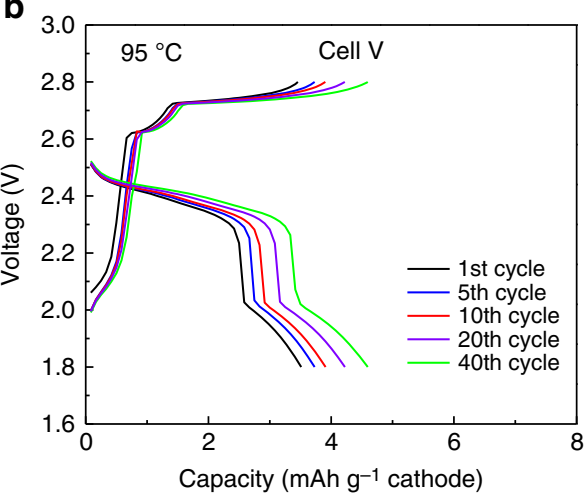

d

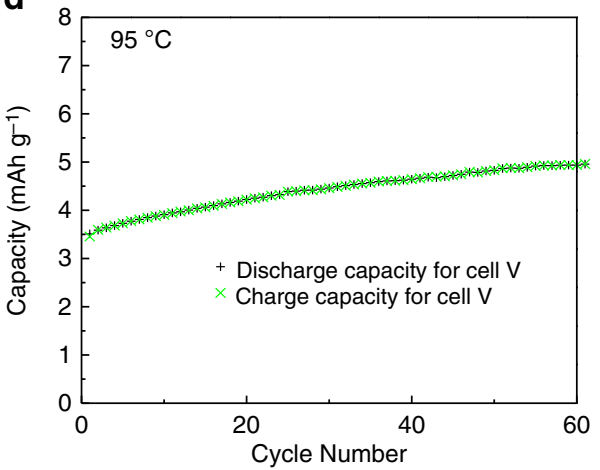

Figure 5 | Electrochemical cell performance. Cell IV: Na-Cs/untreated BASE|S with tetraglyme plus $1 \mathrm{M} \mathrm{Nal.} \mathrm{Cell} \mathrm{V:} \mathrm{Na}-\mathrm{Cs} \mid$ untreated BASE|NiCl 2 with $\mathrm{NaCl}$-saturated $\mathrm{AlCl}_{3}-[\mathrm{MEI}] \mathrm{Cl}$. (a) Cell voltage profiles for cell IV during the 1st, 5th, 10th, 20th and 40th cycles at $95^{\circ} \mathrm{C}$. (b) Cell voltage profiles for cell $\vee$ during the 1st, 5th, 10th, 20th and 40th cycles at $95^{\circ} \mathrm{C}$. (c) Discharge/charge capacities for cell IV during cycling. (d) Discharge/charge capacities for cell $\vee$ during cycling.

sodium wettability and cell stability at lower temperatures when pure sodium was replaced with the $\mathrm{Na}-\mathrm{Cs}$ alloy.

It is shown that, even with $10 \mathrm{~mol} \%$ caesium in the alloy, the melting point decreases from 98 to $80^{\circ} \mathrm{C}$ (refs 25-27). Therefore, by using the novel $\mathrm{Na}-\mathrm{Cs}$ alloy as the anode, NBBs can potentially be operated at temperatures below $100{ }^{\circ} \mathrm{C}$. Here, we further demonstrated the performance of NBBs with $\mathrm{Na}-\mathrm{Cs}$ alloy anode at $95^{\circ} \mathrm{C}$. Figure 5 shows the performance of Na-S and $\mathrm{Na}-\mathrm{NiCl}_{2}$ cells with the alloy anode. Amazingly, the $\mathrm{Na}-\mathrm{S}$ cell could be cycled under a constant current of $7 \mathrm{~mA}$ (that is, $\sim \mathrm{C} / 7$ ) with a high capacity of $330 \mathrm{mAhg}^{-1}$ (see Fig. 5a). This high capacity was attributed to the good electrochemical performance of the $\mathrm{Na}-\mathrm{Cs}$ alloy anode, the BASE and the tetraglyme (with $1 \mathrm{M}$ $\mathrm{NaI})$ catholyte at temperatures below $100^{\circ} \mathrm{C}$. Moreover, the cell showed excellent stability with slight degradation in cell capacity during the initial few cycles and almost no change thereafter, as shown in Fig. 5c.

Owing to the relatively high melting point of $\mathrm{NaAlCl}_{4}$ (that is, $157^{\circ} \mathrm{C}$ ), it cannot be used as the catholyte for $\mathrm{Na}-\mathrm{NiCl}_{2}$ battery below $100^{\circ} \mathrm{C}$. Instead, $\mathrm{NaCl}$-saturated $\mathrm{AlCl}_{3}-1$-methyl-3ethylimidazolium chloride $\left(\mathrm{AlCl}_{3} \text {-[MEI]Cl }\right)^{34,35}$ was employed as the catholyte to operate a $\mathrm{Na}-\mathrm{NiCl}_{2}$ cell with a $\mathrm{Na}-\mathrm{Cs}$ alloy anode at these temperatures. Figure $5 \mathrm{~b}$ shows the performance of the cell with $\mathrm{Na}-\mathrm{Cs}$ alloy anode and $\mathrm{AlCl}_{3}-[\mathrm{MEI}] \mathrm{Cl}$ catholyte at $95^{\circ} \mathrm{C}$. Unfortunately, the cell showed much inferior performance when compared with the $\mathrm{Na}-\mathrm{S}$ cell at the same temperature. The initial cell capacity under a constant current of $1 \mathrm{~mA}$ was only $3.5 \mathrm{mAh} \mathrm{g}^{-1}$, and although it gradually increased with cycling, it was still two orders of magnitude lower than that of the Na-S cell (compare Fig. 5a,b). The low performance in the $\mathrm{Na}-\mathrm{NiCl}_{2}$ cell might be related to insufficient electrochemical activity (for example, ionic conductivity) of the $\mathrm{AlCl}_{3}$-[MEI]Cl catholyte compared to tetraglyme with $1 \mathrm{M} \mathrm{NaI}$ in the $\mathrm{Na}-\mathrm{S}$ cell, considering that both cells had an identical anode and electrolyte. Further optimization of the $\mathrm{AlCl}_{3}-[\mathrm{MEI}] \mathrm{Cl}$ catholyte is critical to achieve desirable performance of a $\mathrm{Na}-\mathrm{NiCl}_{2}$ battery at these lower temperatures.

\section{Discussion}

It should be emphasized that a Na-Cs alloy with a Cs content of $80 \mathrm{~mol} \%$ was selected for wetting tests (Fig. 1; Supplementary Fig. 1), while there was much less Cs in the alloy anodes of single cells. For example, a thin layer of liquid $\mathrm{Na}-\mathrm{Cs}$ alloy $(80 \mathrm{~mol} \%$ Cs) was initially coated on the BASE for $\mathrm{Na}-\mathrm{NiCl}_{2}$ cells during fabrication. During first charge, $\mathrm{Ni}$ reacted with $\mathrm{NaCl}$ in the cathode and sodium was gradually generated at the anode side. After full charging, the alloy in the anode had only $6.7 \mathrm{~mol} \% \mathrm{Cs}$ (Supplementary Fig. 6). When the cells were cycled at an SOC of $26-83 \%$, the Cs content in the alloy was between 20.8 and $7.9 \mathrm{~mol} \%$. For $\mathrm{Na}-\mathrm{S}$ cells, since they were started in a fully charged state, an alloy with $6.7 \mathrm{~mol} \% \mathrm{Cs}$ was loaded into the anode chamber during assembly and the cells were cycled in a similar SOC window with a similar amount of Cs in the anode.

In additional to the cell performance, we have further tested wettability of an alloy with $5 \mathrm{~mol} \% \mathrm{Cs}$ (Na:Cs ratio of 95:5). As seen in Supplementary Fig. 3, the wetting was still much better than pure sodium at $100^{\circ} \mathrm{C}$, which was consistent with the celltesting results. On the basis of these discussions, it can be concluded that Cs content in the alloy anode was not necessarily maintained at $80 \mathrm{~mol} \%$, as it was in the wetting measurements. Considering the high cost of caesium metal, with less caesium addition to the anode, the overall material cost of these novel 
$\mathrm{NBBs}$ will be reduced and comparable with the state-of-the-art NBBs.

In conclusion, addition of caesium to sodium markedly improves its wettability on the surface of BASE. According to our computational and experimental studies, the improvement is related to lower surface tension of liquid caesium metal, and stronger interactions between Cs and $\beta^{\prime \prime}$-alumina atoms compared with those with sodium. Single cells with $\mathrm{Na}-\mathrm{Cs}$ alloy anodes also show marked improvement in cycle life over those with pure sodium anodes. This study implies that the wetting issue in NBBs can be markedly suppressed via addition of other metals such as caesium to the sodium anode. Of course, successful operation of NBBs with high performance at lower temperatures requires us to further address other problems, such as BASE resistance and polarization in the cathodes. This work may also suggest a new approach of using liquid-metal anode and impermeable solid electrolyte for next-generation high-performance batteries, which are intrinsically safer than state-of-the-art room-temperature batteries.

\section{Methods}

BASE fabrication. BASE discs were prepared using a vapour phase process as described previously $7,24,32,36,37 \cdot \alpha-\mathrm{Al}_{2} \mathrm{O}_{3}$ (Almatis, $>99.8 \%$ ), yttria-stabilized zirconia (YSZ) (8YSZ, UCM Advanced Ceramics), dispersant (Phospholan PS-236, Akzo Nobel), solvent (methyl ethyl ketone/ethanol), plasticizer (benzyl butyl phthalate, Aldrich), and binder (Butvar B-79) were thoroughly mixed to make a slurry. The slurry was cast into thin sheets, and the sheets were laminated and laser-cut into circular discs. The discs were fired at $1,600^{\circ} \mathrm{C}$ in air to achieve full density (>99\%). The sintered $\alpha-\mathrm{Al}_{2} \mathrm{O}_{3} / \mathrm{YSZ}$ discs then were placed in a loose $\beta^{\prime \prime}-\mathrm{Al}_{2} \mathrm{O}_{3}$ powder and heat-treated at $1,450{ }^{\circ} \mathrm{C}$ in air to convert $\alpha-\mathrm{Al}_{2} \mathrm{O}_{3}$ into $\beta^{\prime \prime}-\mathrm{Al}_{2} \mathrm{O}_{3}$. The $\beta^{\prime \prime}-\mathrm{Al}_{2} \mathrm{O}_{3}$ powder used for the conversion process was synthesized separately via a solid-state reaction ${ }^{7}$. The thickness of the converted composite $\beta^{\prime \prime}-\mathrm{Al}_{2} \mathrm{O}_{3} / \mathrm{YSZ}$ discs was $\sim 600 \mu \mathrm{m}$.

Wettability test. The sessile drop technique was used to measure the contact angle of liquid sodium or sodium alloys on the BASE surface, as described previously ${ }^{16}$. High-purity Na (Alfa Aesar, 99.95\%), K (Alfa Aesar, 99.96\%), $\mathrm{Rb}$ (Alfa Aesar, 99.95\%) and Cs (Alfa Aesar, 99.98\%) were selected as the starting materials. The as-received BASE samples without any surface modifications or treatments were heated on a hot plate in an argon-protected glove box to the desired temperatures. Some BASE samples coated with lead were also tested for comparison. During the process, the BASE surface was first coated with saturated lead acetate aqueous solution and then heat-treated in an argon-protected atmosphere at $400^{\circ} \mathrm{C}$ to decompose the lead acetate to lead oxide, which was reduced to lead metal during testing. Pure sodium or sodium alloys were heated to the testing temperatures and drops of the liquid metal were transferred to the surface of the BASE using a glass pipette. The wettability test was carried out in a temperature range from room temperature to up to $350^{\circ} \mathrm{C}$ with a holding time of $30 \mathrm{~min}$ at each temperature for wetting-angle measurements.

Computational modelling. Ab initio molecular dynamics simulations were carried out using the density functional theory with a spin-polarized gradient-corrected functional for exchange and correlation as implemented in the CP2K software package (www.cp2k.org.) ${ }^{38-40}$. The wave functions were expanded in a double-zeta Gaussian basis set ${ }^{41}$. An auxiliary plane-wave basis ${ }^{42}$ with 480 Ry energy cutoff was used in the calculation of the electrostatic energy terms. Core electrons were modelled by scalar relativistic norm-conserving pseudopotentials ${ }^{43-45}$ and the $\Gamma$-point approximation was employed for Brillouin zone integration. All $a b$ initio molecular dynamics simulations were performed by sampling the canonical (NVT) ensemble employing Nose-Hoover thermostats ${ }^{46,47}$. After the equilibration phase of $3.0 \sim 5.0 \mathrm{ps}$ (depending on the temperature), the well-equilibrated structure at the specific temperature was analysed.

The liquid-metal or alloy droplet over $\beta^{\prime \prime}$-alumina substrate was modelled with a fifty-atom metal or alloy cluster $\left(\mathrm{Na}_{50}, \mathrm{Cs}_{50}, \mathrm{Na}_{40} \mathrm{Cs}_{10}\right.$ and $\left.\mathrm{Na}_{10} \mathrm{Cs}_{40}\right)$ interacting with the periodic $\beta^{\prime \prime}$-alumina surface slab. All periodic simulation systems included a 30 - $\AA$ vacuum layer between periodic images in the $\mathrm{Z}$ direction. The initial configurations of the metal or alloy clusters were taken from their crystal bulk structures. The $\beta^{\prime \prime}$-alumina used in the simulation had a slab size of $29.2593 \times 33.4500 \times 5.6300 \AA$ and a composition of $\mathrm{Na}_{30} \mathrm{Al}_{198} \mathrm{O}_{306}$. A qualitative description of the wettability can be given by height of the droplet (pseudo-spherical) and width (diameter) of the interfacial area (pseudocircular). Considering the large size difference between $\mathrm{Na}$ and $\mathrm{Cs}$ atoms $(\mathrm{Cs}: \mathrm{Na}=1.43)^{25-27}$, the comparable heights and widths of $\mathrm{Na}$ and $\mathrm{Na}$-rich droplets were scaled by a factor of 1.43 .
Catholyte synthesis. In the current study, a catholyte of $\mathrm{NaAlCl}_{4}$ was used when the $\mathrm{Na}-\mathrm{NiCl}_{2}$ battery was operated at $175^{\circ} \mathrm{C} . \mathrm{NaAlCl}_{4}$ was synthesized by mixing $\mathrm{NaCl}$ (Alfa Aesar, 99.95\%) and $\mathrm{AlCl}_{3}$ (Alfa Aesar, 99.99\%) with a molar ratio of $1.15: 1$, followed by heat treatment at $320^{\circ} \mathrm{C}$ in an argon-filled glove box. A roomtemperature molten salt of $\mathrm{NaCl}$-saturated $\mathrm{AlCl}_{3}$-1-methyl-3-ethylimidazolium chloride $([\mathrm{MEI}] \mathrm{Cl})$ was selected as the catholyte for $\mathrm{Na}-\mathrm{NiCl}_{2}$ batteries operated at $150{ }^{\circ} \mathrm{C}$ or lower ${ }^{34,35}$. It was prepared by mixing $\mathrm{AlCl}_{3}$ (Alfa Aesar, 99.99\%) and [MEI]Cl (Alfa Aesar, 99.99\%) with a molar ratio of $4: 1$ at $150{ }^{\circ} \mathrm{C}$ in the argon-filled glove box. The melt was purified by immersing Al foil (Alfa Aesar, 99.99\%) into the melt. Excess anhydrous $\mathrm{NaCl}$ (Alfa Aesar, 99.99\%) was then added into the melt and heated at the same temperature overnight. For the $\mathrm{Na}-\mathrm{S}$ battery, tetraglyme containing $1 \mathrm{~mol} \mathrm{NaI}$ was selected as the catholyte as before ${ }^{32}$.

Cell construction and testing. Single cells were fabricated as described previously $24,32,36,37$. BASE discs with a diameter of $26 \mathrm{~mm}$ were glass-sealed to $\alpha-\mathrm{Al}_{2} \mathrm{O}_{3}$ rings with an active cell area of $\sim 3 \mathrm{~cm}^{2}$. Some of the glass-sealed $\alpha-\mathrm{Al}_{2} \mathrm{O}_{3}$ rings were further treated by coating the anode side of the BASE surface with a thin layer of lead. The cell assembly then was moved into the argon-filled glove box. For the $\mathrm{Na}-\mathrm{NiCl}_{2}$ battery, $1 \mathrm{~g}$ of cathode granules consisting of $\mathrm{Ni}, \mathrm{NaCl}$ and small amounts of additives were put into the cathode chamber ${ }^{24}$. Molten catholyte of $\mathrm{NaAlCl}_{4}$ or $\mathrm{NaCl}$-saturated $\mathrm{AlCl}_{3}-[\mathrm{MEI}] \mathrm{Cl}$ was infiltrated into the cathode. For the $\mathrm{Na}-\mathrm{S}$ battery, the catholyte of NaI-containing tetraglyme was heated to $150{ }^{\circ} \mathrm{C}$ and a mixture of $\mathrm{S}$ and $\mathrm{Na}_{2} \mathrm{~S}_{4}$ (molar ratio of 4:1) was dissolved into the solution ${ }^{32}$. The solution was poured into the cathode chamber and a carbon felt was inserted into the chamber as a current collector.

A foil and spring made of Mo were placed on top of the cathode as a current collector. When liquid $\mathrm{Na}-\mathrm{Cs}$ alloy was used as the anode, a thin layer of the alloy $(0.06 \mathrm{~g}$, molar ratio of 1:4) was brushed onto the surface of pristine BASE. If pure sodium was selected as the anode, a small piece of sodium was preloaded onto the lead-coated BASE for initial contact. For the Na-S battery, since it was assembled in a fully charged state, the desired amount of sodium or $\mathrm{Na}-\mathrm{Cs}$ alloy was added into the anode chamber during assembly. A spring-loaded stainless steel shim was inserted into the compartment as molten sodium reservoir. Anode and cathode end plates were then compression-sealed to both sides of the $\alpha-\mathrm{Al}_{2} \mathrm{O}_{3}$ ring using silver O-rings. Nickel leads, which served as current collectors, were welded to the electrode end plates. The assembled cells were heated in air to the desired temperatures. The galvanostatic discharge/charge test was carried out with a BT-2000 Arbin Battery Testing system as before $24,32,36,37$.

\section{References}

1. Palomares, V. et al. Na-ion batteries, recent advances and present challenges to become low cost energy storage systems. Energy Environ. Sci. 5, 5884-5901 (2012).

2. Pan, H., Hu, Y.-S. \& Chen, L. Room-temperature stationary sodium-ion batteries for large-scale electric energy storage. Energy Environ. Sci. 6, 2338-2360 (2013).

3. Kim, H. et al. Liquid metal batteries: past, present, and future. Chem. Rev. 113, 2075-2099 (2013).

4. Deshpande, R. D., Li, J., Cheng, Y.-T. \& Verbrugge, M. W. Liquid metal alloys as self-healing negative electrodes for lithium ion batteries. J. Electrochem. Soc. 158, A845-A849 (2011).

5. Liu, G. \& Wang, D. D. Low temperature sulfur and sodium metal battery for grid-scale energy storage application. US patent PCT/US2013/032465 (2014).

6. Yang, Z. et al. Electrochemical energy storage for green grid. Chem. Rev. 111, 3577-3613 (2011).

7. Lu, X., Xia, G., Lemmon, J. P. \& Yang, Z. Advanced materials for sodium-beta alumina batteries: status, challenges and perspectives. J. Power Sources 195, 2431-2442 (2010).

8. Kummer, J. T. \& Weber, N. Battery having a molten alkali metal anode and a molten sulfur cathode. US patent 3,413,150 (1968).

9. NGK Insulators Ltd. Reference Installations (2011), http://www.ngk.co.jp/ english/products/power/nas/installation/index.html.

10. Sudworth, J. L. \& Tilley, A. R. The Sodium Sulphur Battery (Chapman \& Hall, 1985).

11. Gibson, A. Power Sources. (ed. Collins, D. H.) Ch. 6 (Academic Press, 1977).

12. Breiter, M. W., Dunn, B. \& Powers, R. W. Asymmetric behavior of beta" alumina. Electrochim. Acta 25, 613-616 (1980).

13. Demott, D. S. Resistance rise in sodium-sulfur cells. J. Electrochem. Soc. 127, 2312-2313 (1980).

14. Lehnert, G. \& Hartmann, B. Ext. Abstr. No. 335, Electrochemical Society Meeting (Detroit, MI, 1982).

15. Viswanathan, L. \& Virkar, A. V. Wetting characteristics of sodium on $\beta^{\prime \prime}$-alumina and on nasicon. J. Mater. Sci. 17, 753-759 (1982).

16. Reed, D. M. et al. Wetting of sodium on $\beta^{\prime \prime}-\mathrm{Al}_{2} \mathrm{O}_{3} / \mathrm{YSZ}$ composites for low temperature planar sodium-metal halide batteries. J. Power Sources 227, 94-100 (2013).

17. Bugden, W. G., Barrow, P. \& Duncan, J. H. The control of the resistance rise of sodium sulphur cells. Solid State Ionics 5, 275-278 (1981). 
18. Jones, I. W. \& Miles, L. J. Production of $\beta-\mathrm{Al}_{2} \mathrm{O}_{3}$ electrolyte. Proc. Br. Ceram. Soc. 19, 161-178 (1971).

19. Buechele, A. C. \& De Jonghe, L. C. Microstructure and ionic resistivity of calcium-containing sodium beta alumina. Am. Ceram. Soc. Bull. 58, 861-864 (1979).

20. Demott, D. S., Wright, M. L. \& Hames, M. D. Ext. Abstr. No. 469, Electrochemical Society Meeting (Minneapolis, MN, 1981).

21. NGK Insulators Ltd. NAS battery fire incident and response (2011), http:// www.ngk.co.jp/english/announce/index.html.

22. Wright, M. L. Beta alumina solid electrolyte material and its manufacture and electrochemical cells or other energy conversion devices containing such material. British Patent. 2,067,005 (1981).

23. Wright, M. L. \& Hames, M. D. Sodium sulphur cells. British Patent. 2,080,608 (1982).

24. Lu, X. et al. The effects of temperature on the electrochemical performance of sodium-nickel chloride batteries. J. Power Sources 215, 288-295 (2012).

25. Bale, C. W. The K-Na (potassium-sodium) system. Bull. Alloy Phase Diagrams 3, 313-318 (1982)

26. Bale, C. W. The Na-Rb (sodium-rubidium) system. Bull. Alloy Phase Diagrams 3, 318-321 (1982)

27. Bale, C. W. The Cs-Na (cesium-sodium) system. Bull. Alloy Phase Diagrams 3, 310-313 (1982)

28. Yao, Y. -F. Y. \& Kummer, J. T. Ion exchange properties of and rates of ionic diffusion in beta-alumina. J. Inorg. Nucl. Chem. 29, 2453-2475 (1967).

29. Koh, J.-H., Weber, N. \& Virkar, A. V. Synthesis of lithium-beta-alumina by various ion-exchange and conversion processes. Solid State Ionics 220, 32-38 (2012).

30. Adamson, A. W. Physical Chemistry of Surfaces 5th edn 403-408 (Wiley, 1990).

31. Bohdansk, J. \& Schins, H. E. J. The surface tension of the alkali metals. J. Inorg. Nucl. Chem. 29, 2173-2179 (1967).

32. Lu, X. et al. Advanced intermediate-temperature Na-S battery. Energy Environ. Sci. 6, 299-306 (2013).

33. Ryu, H. et al. Discharge reaction mechanism of room-temperature sodiumsulfur battery with tetra ethylene glycol dimethyl ether liquid electrolyte. J. Powers Sources 196, 5186-5190 (2011).

34. Ui, K., Minami, T., Ishikawa, K., Idemoto, Y. \& Koura, N. Development of nonflammable lithium secondary battery with ambient-temperature molten salt electrolyte: Performance of binder-free carbon-negative electrode. J. Power Sources 146, 698-702 (2005).

35. Dymek, C. J., Reynolds, G. F. \& Wilkes, J. S. A rechargeable cadmium-bromine battery using room temperature chloroaluminate molten salts. J. Electrochem. Soc. 134, 1658-1663 (1987)

36. Lu, X. et al. High power planar sodium-nickel chloride battery. ECS Trans. 28, 7-13 (2010).

37. Lu, X. et al. A novel low-cost sodium-zinc chloride battery. Energy Environ. Sci. 6, 1837-1843 (2013)

38. Krack, M. \& Parrinello, M. All-electron ab-initio molecular dynamics. Phys. Chem. Chem. Phys. 2, 2105-2112 (2000).

39. VandeVondele, J. \& Hutter, J. An efficient orbital transformation method for electronic structure calculations. J. Chem. Phys. 118, 4365-4369 (2003).
40. VandeVondele, J. et al. Quickstep: fast and accurate density functional calculations using a mixed Gaussian and plane waves approach. Comput. Phys. Commun. 167, 103-128 (2005)

41. VandeVondele, J. \& Hutter, J. Gaussian basis sets for accurate calculations on molecular systems in gas and condensed phases. J. Chem. Phys. 127, 114105 (2007).

42. Lippert, G., Hutter, J. \& Parrinello, M. A hybrid Gaussian and plane wave density functional scheme. Mol. Phys. 92, 477-487 (1997).

43. Kresse, G. \& Furthmuller, J. Efficient iterative schemes for ab initio total-energy calculations using a plane-wave basis set. Phys. Rev. B Condens. Matter 54, 11169-11186 (1996).

44. Kresse, G. \& Furthmuller, J. Efficiency of ab-initio total energy calculations for metals and semiconductors using a plane-wave basis set. Comput. Mater. Sci. 6, 15-50 (1996).

45. Kresse, G. \& Hafner, J. Ab initio molecular-dynamics simulation of the liquid-metal-amorphous-semiconductor transition in germanium. Phys. Rev. B Condens. Matter 49, 14251-14269 (1994)

46. Hoover, W. G. Canonical dynamics: equilibrium phase-space distributions. Phys. Rev. A 31, 1695-1697 (1985)

47. Nose, S. A unified formulation of the constant temperature molecular dynamics methods. J. Chem. Phys. 81, 511-519 (1984).

\section{Acknowledgements}

We thank N. Canfield for the BASE conversion, B.W. Kirby for the glass seal and D.R. Herling, D. Reed and J. Holladay for discussion and suggestions. The work was supported by the Laboratory-Directed Research and Development Program of Pacific Northwest National Laboratory (PNNL) and the US Department of Energy's (DOE's) Office of Electricity Delivery \& Energy Reliability (OE). We appreciate useful discussions with Dr I. Gyuk of the DOE-OE Grid Storage Program. PNNL is a multi-program laboratory operated by Battelle Memorial Institute for the Department of Energy under Contract DE-AC05-76RL01830.

\section{Author contributions}

X.L. and J.Y.K. conceived and designed the experiments. X.L. synthesized and characterized the materials, and performed the experiments. D.M. and J.L. conceived the simulation protocol, and D.M. carried out the simulations. X.L. and D.M. analysed the data, and X.L. wrote the manuscript. X.L., G.L., J.Y.K., D.M., J.P.L., V.L.S. and J.L. discussed the results and commented on the manuscript

\section{Additional information}

Supplementary Information accompanies this paper at http://www.nature.com/ naturecommunications

Competing financial interests: The authors declare no competing financial interests

Reprints and permission information is available online at http://npg.nature.com/ reprintsandpermissions/

How to cite this article: Lu, X. et al. Liquid-metal electrode to enable ultra-low temperature sodium-beta alumina batteries for renewable energy storage. Nat. Commun. 5:4578 doi: 10.1038/ncomms5578 (2014). 